\title{
Isolation, Characterization and Derivatization of Some Bioactive Components in Moringa Oleifera Leaves
}

\section{Ogundele VA ${ }^{1 *}$ and Fadeyi $\mathrm{OE}^{2}$}

${ }^{1}$ Department of Chemical, Geological and Physical Sciences, Kwara State University Malete, Ilorin, Nigeria

${ }^{2}$ Department of Chemistry, University of Ilorin, Ilorin, Nigeria

\begin{abstract}
Moringa oleifera is an important multipurpose tropical tree not yet fully investigated for its medicinal and therapeutic properties which informed the objective for this research work. The $M$. oleifera n-hexane leaves extract yielded a solid substance that was re-crystallized several times to obtain a relatively pure compound which was subsequently derivatized. The FTIR data of the solid substance indicated that the substance is an aliphatic alcohol. Consequently, it was derivatized to an ester, an aldehyde and a carboxylic acid.
\end{abstract}

Keywords: Re-crystallized; Aliphatic alcohol; Solid substance

\section{Introduction}

Moringa oleifera is a member of Moringaceae family which grows throughout the tropics. It is native to sub-Himalayan tribes of North West India, Pakistan, Bangladesh and Afghanistan, but now distributed worldwide in the tropics and found in many countries of Africa and South America. It was well known to the ancient world, but recently has been "rediscovered" as a multipurpose tree with tremendous variety of potential uses. The leaves, flowers, fruits and roots of Moringa are used as vegetables; the seeds for water purification, and the oil extracted is used for cooking, soap manufacture, as a cosmetic base and to provide illumination [1]. Other uses include cattle fodder, biogas production, and all plant organs are used as constituent in traditional medicine [2]. In Africa the cooked leaves of Moringa are eaten as principal ingredients of sauce, but in Northern Nigeria the leaves are used as vegetable in soup preparation, while the root poultice is used to treat inflammation especially swelling tissue or oedema $[1,3]$.

\section{Materials and Methods}

\section{Collection and identification of plant materials}

Fresh leaves of Moringa oleifera were collected from Gaa-Akanbi area in Ilorin Kwara State, Nigeria. The plant samples were identified as Moringa oleifera leaves and documented in the herbarium at the Department of Plant Biology, University of Ilorin, Nigeria.

\section{Extract preparation}

The plant leaves were dried at room temperature to remove moisture. It was then pulverized to increase the surface area for extraction. $1000 \mathrm{~g}(1 \mathrm{~kg})$ of the pulverized leaves of Moringa oleifera was soaked in distilled $n$-hexane at room temperature for seven days. The crude extract obtained was decanted and filtered. The crude extracts obtained were later concentrated in vacuo to remove the n-hexane used for the extraction process. The weight of the crude extract was $37.8 \mathrm{~g}$.

\section{Thin layer chromatography}

Thin layer chromatography analyses of the crude extract of the leaves of $M$. oleifera were carried out. The solvent system used for development was DCM/diethyl ether/n-hexane (1:1:1). After development, the TLC plates were allowed to dry and viewed under the UV-lamp at 254 and $366 \mathrm{~nm}$.

\section{Chromatographic purification and isolation}

In order to obtain pure isolates, the crude extracts were fractionated using Column Chromatography (CC). The precipitated substance from the major fraction was re-crystallized several times so as to obtain a relatively pure compound which was then derivatized.

Column Chromatography (cc) of the crude extracts: $15.0 \mathrm{~g}$ of the crude extract was subjected to an open column chromatography on silica gel (100-120 mesh grade) using a glass column $(5 \mathrm{~cm}$ diameter and $45 \mathrm{~cm}$ long).

\section{Derivatization}

The following reagents were used to derivatize the isolate;

Cinnamic acid and salicylic acid were used to esterify the isolate.

The hydroxyl functional group (IR) was also oxidized using Jones reagent.

Esterification using salicylic acid: $0.255 \mathrm{~g}$ of salicylic acid and $0.258 \mathrm{~g}$ of the relatively pure compound were weighed into a boiling tube and then inserted in a sand bath, the esterification reaction was carried out using melt method at $260^{\circ} \mathrm{C}$ for 10 minutes.

Esterification using cinnamic acid: $0.670 \mathrm{~g}$ of cinnamic acid and $0.67 \mathrm{~g}$ of the relatively pure compound were weighed into a boiling tube and then inserted in a sand bath, the esterification reaction was carried out using melt method at $260^{\circ} \mathrm{C}$ for 10 minutes.

Oxidation using jones reagent: The isolate was oxidized using Jones reagent (solution of potassium dichromate in dilute sulphuric acid) in the presence of acetone. $10 \mathrm{ml}$ of the Jones reagent was measured into a $50 \mathrm{ml}$ conical flask placed in ice cold water and $1.25 \mathrm{~g}$ of the isolated compound was weighed and added into a $50 \mathrm{ml}$ conical flask and the mixture was stirred on a magnetic stirrer. The reaction mixture was filtered and the bluish residue obtained was dissolved in a mixture of DCM/n-hexane (1:1). On heating, some part of the residue was found to remain insoluble so the mixture was re-filtered. A bluish

*Corresponding author: Ogundele VA, Department of Chemical, Geological and Physical Sciences, Kwara State University Malete, P.M.B 1530, Ilorin, Nigeria, Tel: 2348062667993; E-mail: vicshow2001@gmail.com

Received September 04, 2015; Accepted September 18, 2015; Published September 24, 2015

Citation: Ogundele VA, Fadeyi OE (2015) Isolation, Characterization and Derivatization of Some Bioactive Components in Moringa Oleifera Leaves. Nat Prod Chem Res 3: 189. doi:10.4172/2329-6836.1000189

Copyright: ( 2015 Ogundele VA, et al. This is an open-access article distributed under the terms of the Creative Commons Attribution License, which permits unrestricted use, distribution, and reproduction in any medium, provided the original author and source are credited. 
solid residue was collected and transferred into a sample bottle for analysis. The whitish filtrate was collected and transferred into a sample bottle for analysis.

\section{Results and Discussion}

\section{Column chromatography of the crude extract}

The components of the $n$-hexane crude extract were isolated using glass column packed with silica gel; n-hexane and dichloromethane were used as eluents. Thirty-five fractions were obtained and collected in $50 \mathrm{ml}$ flasks after which identical fractions were pooled into 10 combined fractions.

\section{Derivatization of the crystalline substance}

The FTIR of the isolated crystalline compound indicated the presence of -OH stretching at $3412.19 \mathrm{~cm}^{-1}$ as the only diagnostic signal which suggests that the compound is likely to be an alcohol. Effort was made to derivatize the substance to an ester using the melt method, while Jones reagent was used to oxidize the substance to an aldehyde and carboxylic acid.

FTIR analyses of the isolates and derivatized compounds (M3C, M4D) (M3C and M4D are isolates from column chromatography), Moringa extract powder, OSR (bluish solid residue), OF (Whitish filtrate))

From the IR spectra of the isolated compounds, the bands observed are summarized in the Table 1 .

FTIR of M3C: The isolate with the code M3C, showed the $-\mathrm{OH}$ stretching vibration at $3437.26 \mathrm{~cm}^{-1}$, aliphatic C-H stretching at 2850 $\mathrm{cm}^{-1}$. The $\mathrm{C}=\mathrm{O}$ stretching of an ester appeared at $1739 \mathrm{~cm}^{-1}$, the peak at $1377 \mathrm{~cm}^{-1}$ indicates the $\mathrm{C}-\mathrm{O}$ stretching of an ester, while the $\mathrm{C}-\mathrm{H}$ bend appeared at $1464 \mathrm{~cm}^{-1}$. Therefore, it is speculated that this isolate is an aliphatic hydroxyl ester with an hypothetical structure as shown in Figure 1.

FTIR of M4D: The -OH vibration stretching appeared at 3439.19 $\mathrm{cm}^{-1}$, aliphatic C-H stretch at $2955.04 \mathrm{~cm}^{-1}$ and $2850.88 \mathrm{~cm}^{-1}$. The absorption peaks at $1739.85 \mathrm{~cm}^{-1}$ indicates the $\mathrm{C}=\mathrm{O}$ stretching of an ester while the peak at $1377.22 \mathrm{~cm}^{-1}$ confirmed the presence of $\mathrm{C}-\mathrm{O}$ stretching of an ester. The peaks at $1464.02 \mathrm{~cm}^{-1}$ indicated the $\mathrm{C}-\mathrm{H}$ bending. This isolate has similar spectral data to that of $\mathrm{M} 3 \mathrm{C}$ and therefore, M4D and M3C might be identical compounds.

FTIR of Moringa extract powder: The main IR absorption peaks are $\mathrm{O}-\mathrm{H}$ stretching that appeared at $3412.0 \mathrm{~cm}^{-1}$, aliphatic $\mathrm{C}-\mathrm{H}$ stretching frequencies at $2945.00 \mathrm{~cm}^{-1}$ and $2855.0 \mathrm{~cm}^{-1}$. The peaks at $1474.00 \mathrm{~cm}^{-1}$ and $1454.0 \mathrm{~cm}^{-1}$ indicates the $\mathrm{C}-\mathrm{H}$ bending. Therefore, the presence of only aliphatic $\mathrm{C}-\mathrm{Hs}$ and alcohol $\mathrm{O}-\mathrm{H}$ could be deduced to suggest the presence of a saturated aliphatic alcohol with a long alkyl chain.
FTIR of OF: The FTIR data obtained for OF showed the C-H stretching at $2918.40 \mathrm{~cm}^{-1}$ and $2848.96 \mathrm{~cm}^{-1}$ while the stretch at 1683.91 $\mathrm{cm}^{-1}$ can be attributed to an $\alpha, \beta$-unsaturated carbonyl compound which can be said to be responsible for the lowering of the carbonyl stretching. The $\mathrm{C}=\mathrm{C}$ stretching occurs at $1604.83 \mathrm{~cm}^{-1}$ and a C-H bend at 1429.30 $\mathrm{cm}^{-1}$. OF is likely to be an aldehyde due to the presence of a moderate $\mathrm{H}-\mathrm{C}=\mathrm{O}$ stretching at $2848.96 \mathrm{~cm}^{-1}$. The likely general structure deduceable from this spectral data is shown in Figure 2.

FTIR of OSR: The FTIR data obtained for OSR showed the -OH vibration frequency at $3400.62 \mathrm{~cm}^{-1}$, aliphatic C-H stretching at 2953.12 $\mathrm{cm}^{-1}$ and $2855.00 \mathrm{~cm}^{-1}$. The stretch at $1716.70 \mathrm{~cm}^{-1}$ indicated the $\mathrm{C}=\mathrm{O}$ of an acid, while $\mathrm{C}-\mathrm{O}$ stretch of acid is confirmed by the absorption peak at $1111.03 \mathrm{~cm}^{-1}$ while $1464.02 \mathrm{~cm}^{-1}$ indicated $\mathrm{C}-\mathrm{H}$ bending. The aldehyde (OF) previously obtained was further oxidized to the corresponding carboxylic acid.

\section{GC-MS analyses results}

GC-MS analyses of two reaction products were carried out. The GC-MS data of the products are presented in the Table 2.

The GC-MS Spectrum of the oxidized product (OSR) above showed that the product is a mixture of two acids and an ester, it can be seen from the Table 2 that the two acids make up $66.38 \%$ of the total composition while that of the ester is $33.62 \%$ of the total constituents. Therefore, it can be concluded that the Moringa extract powder was successfully oxidized to an acid as suggested by FTIR spectral data.

9-Octadecenoic acid (z)-, 2-hydroxy-1-(hydroxymethyl)ethyl ester though not a major component of the oxidized product, has been reported to inhibit the proliferative effect in keloid fibroblasts [4] and (z,z)-9,12-octadecadienoic acid also known as linoleic acid can be used to show the antioxidant effect of natural phenols [5].

n-hexadecanoic acid which happens to be the major constituent proposed by the NIST library for the oxidized product has been reported in literature to be probably responsible for the yellow colour of many plants [6], and also reported to be among the fatty acids which possess antibacterial and antifungal activity $[7,8]$. The mass spectral data for this compound confirms its molecular mass as 256 and the base peak as 73. Therefore, the structure for this compound (59) and its fragmentation pattern are given in the Scheme 1.

From Table 3 GC-MS spectral data for CMP, only one peak was observed which implies that it is a pure reaction product. The structure proposed by the NIST library has been modified due to the disparity in the matching of its mass spectra and the compound's mass spectra. The molecular mass of the NIST library suggestion is 147 while that of the matched compound is 207; hence the need to modify the structure to obtain a compound whose spectra matches to a large extent that obtained from the GC-MS.

\begin{tabular}{|c|c|c|c|c|c|c|c|}
\hline S No & SAMPLE CODE & $\begin{array}{c}\mathbf{U}_{\mathrm{OH}^{-1}} \\
\left(\mathrm{~cm}^{-1}\right)\end{array}$ & $\begin{array}{l}\mathbf{U}_{\text {Aliph.c.-H }} \\
\left(\mathrm{cm}^{-1}\right)\end{array}$ & $\begin{array}{l}U_{\mathrm{c}=\mathrm{O}} \\
\left(\mathrm{cm}^{-1}\right)\end{array}$ & $\begin{array}{l}U_{\mathrm{c}=\mathrm{c}} \\
\left(\mathrm{cm}^{-1}\right)\end{array}$ & $\begin{array}{c}\mathbf{u}_{\mathrm{c-o}} \\
\left(\mathbf{c m}^{-1}\right)\end{array}$ & $\begin{array}{c}\mathrm{U}_{\mathrm{C-H}}\left(\mathrm{bmend}^{-1}\right) \\
\left(\mathrm{cm}^{-1}\right)\end{array}$ \\
\hline 1 & $\mathrm{M} 3 \mathrm{C}$ & 3437.26 & 2850.88 & 1739.85 & & 1377.22 & 1464.02 \\
\hline 2 & M4D & 3439.19 & $\begin{array}{l}2955.04 \\
2850.88\end{array}$ & 1739.85 & & 1377.22 & 1464.02 \\
\hline 3 & Powder & 3412.00 & $\begin{array}{l}2945.00 \\
2855.00\end{array}$ & & & & $\begin{array}{l}1474.00 \\
1454.00\end{array}$ \\
\hline 4 & OSR & 3400.62 & $\begin{array}{l}2953.12 \\
2855.00\end{array}$ & 1716.70 & & 1111.03 & 1464.02 \\
\hline 5 & OF & & $\begin{array}{l}2918.40 \\
2848.96\end{array}$ & 1683.91 & 1604.83 & 1168.90 & 1429.30 \\
\hline
\end{tabular}

Table 1: Characteristic FTIR of the Isolates and the Derivatized Compounds. 
<smiles>[R]CCC(=O)OC(O)C[R]</smiles>

Figure 1: Hypothetical structure proposed for FTIR of M3C.<smiles>[R]C=CC=O</smiles>

Figure 2: Hypothetical structure proposed for OF.

\begin{tabular}{|c|c|c|c|c|}
\hline $\begin{array}{l}\text { S } \\
\text { No }\end{array}$ & $\begin{array}{l}\text { Name of Proposed } \\
\text { compound }\end{array}$ & $\begin{array}{l}\text { Ret. } \\
\text { Time }\end{array}$ & $\begin{array}{l}\% \\
\text { Composition }\end{array}$ & $\begin{array}{l}\text { Mass spectra } \\
\text { data }\end{array}$ \\
\hline 1. & n-hexadecanoic acid & 37.974 & 43.56 & $\begin{array}{l}57,60,73,83,97,115,129 \\
143,157,171,185,199,213 \\
227,239,256\end{array}$ \\
\hline 2. & $\begin{array}{l}\text { 9-Octadecenoic acid } \\
\text { (z)-,2-hydroxy-1- } \\
\text { (hydroxymethyl)ethyl } \\
\text { ester }\end{array}$ & 51.283 & 33.62 & $\begin{array}{l}55,61,69,81.98,109,123,137 \\
, 151,165,180,193,207,221,2 \\
35,247,264,280,295,307,325 \\
, 338,354\end{array}$ \\
\hline 3 & $\begin{array}{l}(z, z)-9,12- \\
\text { octadecadienoic acid }\end{array}$ & 42.866 & 22.82 & $\begin{array}{l}55,69,73,83,97,111,129,157 \\
, 171,185,199,213,227,246,2 \\
64,282\end{array}$ \\
\hline
\end{tabular}

Table 2: GC-MS Analysis of OSR.

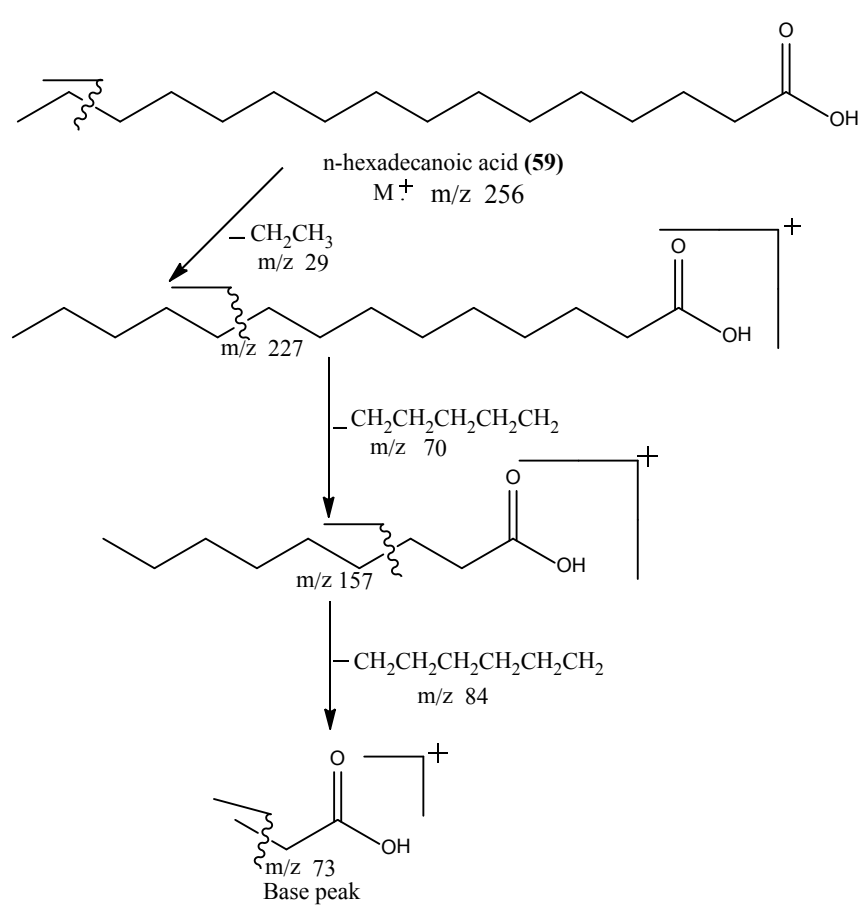

Scheme 1: Mass fragmentation pattern of $n$-hexadecanoic acid.

\begin{tabular}{|l|l|l|l|l|}
\hline S No & $\begin{array}{l}\text { Name of Proposed } \\
\text { Compound }\end{array}$ & $\begin{array}{l}\text { Ret. } \\
\text { Time }\end{array}$ & \% Composition & $\begin{array}{l}\text { Mass spectra } \\
\text { data }\end{array}$ \\
\hline $1 . \quad$ & $\begin{array}{l}\text { Trans-cinnamic } \\
\text { acid }\end{array}$ & 23.320 & 100 & $\begin{array}{l}51,63,77,91,103, \\
120,131,147,207\end{array}$ \\
\hline
\end{tabular}

Table 3: GC-MS Analysis of CMP

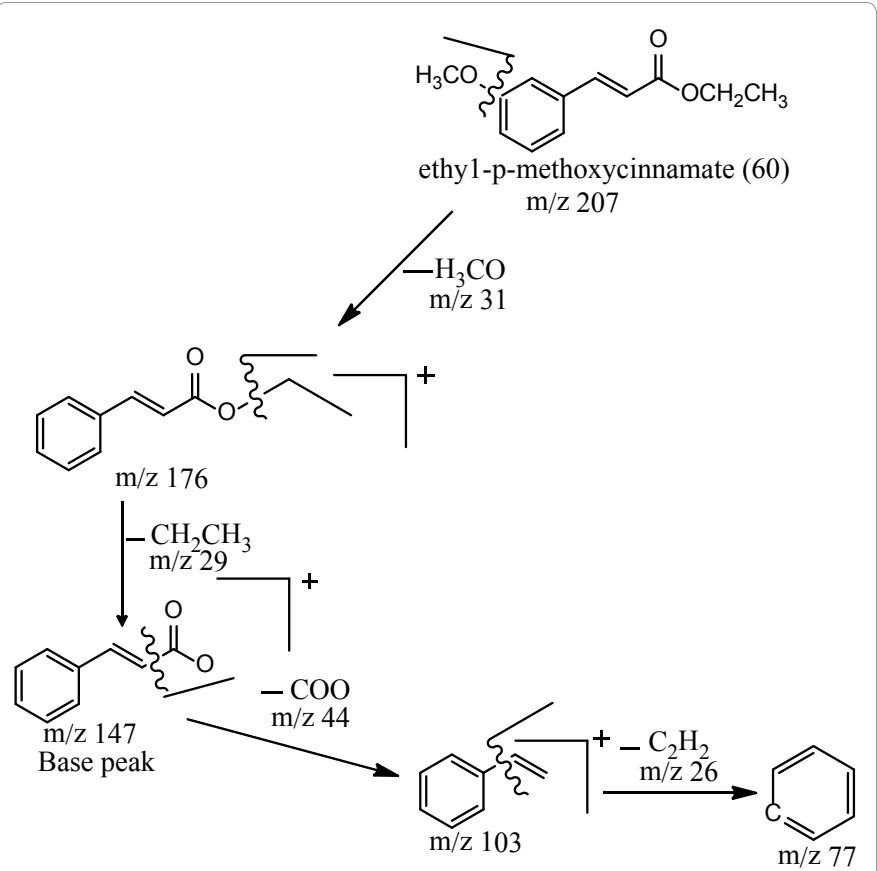

Scheme 2: Proposed structure and fragmentation pattern of ethyl-p-methoxycinnamate.

The name of the new proposed structure is ethyl-pmethoxycinnamate (60) which is an ester, and this showed that the esterification reaction was successful. Ethyl-p-methoxycinnamate (60) has been reported in literature to have larvicidal activity against $A$. aegypti, O. togoi and C. pipens pallens [9].

The proposed structure for this compound (60) and its fragmentation pattern are given in the Scheme 2.

\section{Conclusion}

In this research work, a crystalline substance was isolated from n-hexane extract of pulverized Moringa leaves. The exact structure of this compound is yet to be ascertained. The spectral data available suggest an aliphatic fatty alcohol and this formed the basis for the derivatization of the compound to an ester, aldehyde and carboxylic acid.

\section{Acknowledgement}

The bench work of this research work was carried out in the laboratory of the department of Chemistry, University of Ilorin, while the Infrared spectroscopy was carried out at the Chemical Research Laboratory, Redeemer's University, Mowe, Ogun State. We are indeed grateful to Prof. Olatunji of the department of Chemistry, University of Ilorin and Dr. Atolani Olubunmi of the department of Chemical Sciences, Redeemer's University, Mowe, Ogun State.

\section{References}

1. Lowell JE (2001) The Miracle Tree: The multiple attributes of Moringa. Technica Centre for Agricultural and Rural Cooperation (Acp_Eu). Dakar Senegal.

2. Caceres A, Cebera Morale O, Mollideo P, Mendia P (1990) Pharmacologica properties of Moringa oleifera 1: Preliminary Screening for antimicrobial activity. Journal of ethnophamacology 33: 213-216.

3. John MW, Maria GB (1962) The medical and poisonous plant of Southern and Eastern African. 2nd edn. E S Livingstone Ltd, Edinbrugh and London. p: 345.

4. Saleem R (1995) The chemical composition of Moringa oleifera. PhD Thesis, H. E. J. Research Institute of University of Karachi, Pakistan.

5. Peyrat-Maillard MN, Cuvelier ME, Berset C (2003) Antioxidant activity of phenolic compounds in 2,2'-azobis (2-amidinopropane) dihydrochloride (AAPH)-induced oxidation: Synergistic and antagonistic effects. Journal of the American Oil Chemists Society 80: 1007-1012. 
Citation: Ogundele VA, Fadeyi OE (2015) Isolation, Characterization and Derivatization of Some Bioactive Components in Moringa Oleifera Leaves. Nat Prod Chem Res 3: 189. doi:10.4172/2329-6836.1000189

6. Wang GYS, Graziani E, Waters B, Pan W, Li X, McDermott J, et al. (2000) Novel Natural Products from Soil DNA Libraries in a Streptomycete Host. Org Lett 2: 2401-2404.

7. Mcgraw KJ, Bai VD, Krishnakumar S (2013) Evaluation of antimicrobial metabolites from marine microalgae Tetraselmis suecica using gas chromatography-mass spectrometry (GC-MS) analysis. Int J Pharm Sci 5: 17-23.
8. Seidel, Taylor (2004) In vitro activity of extracts and constituents of pelargonium against rapidly growing mycobacteria. Int J Antimicrob Agents 23: 613-619.

9. Kim SL, Kurup PA, PLN Rao (2008) The importance of using scientific principles in the development of medicinal agents from plants. Curr Sci 19: 54 